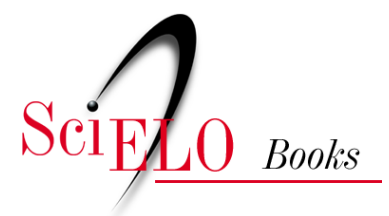

\title{
EDUFU
}

\section{Natureza, sociedade e educação elementos para uma leitura contextualizada de Emílio, de Jean Jacques Rousseau}

\author{
Ana Carolina Theodoro
}

\section{SciELO Books / SciELO Livros / SciELO Libros}

THEODORO, A.C. Natureza, sociedade e educação: elementos para uma leitura contextualizada de Emílio, de Jean Jacques Rousseau. In: BOTO, C., ed. Clássicos do pensamento pedagógico: olhares entrecruzados [online]. Uberlândia: EDUFU, 2019, pp. 43-69. História, Pensamento, Educação collection. Novas Investigações series, vol. 9. ISBN: 978-65-5824-027-3. Available from: http://books.scielo.org/id/fjnhs/pdf/boto9786558240273-04.pdf. https://doi.org/10.14393/edufu-978-85$7078-472-8$.

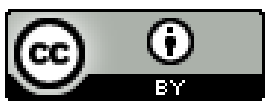

All the contents of this work, except where otherwise noted, is licensed under a Creative Commons Attribution 4.0 International license.

Todo o conteúdo deste trabalho, exceto quando houver ressalva, é publicado sob a licença Creative Commons Atribição 4.0.

Todo el contenido de esta obra, excepto donde se indique lo contrario, está 


\section{Natureza, sociedade e educação: elementos para uma leitura contextualizada de Emílio, de Jean Jacques Rousseau}

Ana Carolina Theodoro

\section{Introdução}

A História da Educação tem marcos referenciais que são não apenas importantes reflexões teóricas, mas também propostas pedagógicas que exerceram grande influência em práticas educativas. Reconhecendo ser Emílio, ou da educação, de Jean-Jacques Rousseau (Rousseau, 1999b), um escrito do segundo gênero, este artigo pretende oferecer uma leitura contextualizada da obra.

Essa tarefa requer uma visão unitária do pensamento rousseauniano ou, ao menos, uma apreciação que faça dialogar suas distintas obras, sejam elas políticas, filosóficas ou pedagógicas. Concretamente, neste artigo foram analisados o Discurso sobre as ciências $e$ as artes (Rousseau, 1999a), o Discurso sobre a origem e o fundamento das desigualdades entre os homens (Rousseau, 1999a), O contrato social (Rousseau, 1999c) e Emilio (Rousseau, 1999b). Não sendo possível apresentar um estudo exaustivo do seu conteúdo, priorizou-se a seleção e a investigação das seguintes categorias filosóficas: natureza, liberdade, sociedade, pacto social, educação natural e autoridade, além da categoria pedagógica de infância. Dessa forma, há maior 
possibilidade de se obter uma visão transversal de tais conceitos, de observar a complementação dos distintos significados e a relação destes com a proposta educativa rousseauniana.

A pesquisa se enquadra, desse modo, em uma perspectiva relacional que une antropologia, filosofia política e educação em Rousseau. Para ele, a educação é política: a preparação do homem para a liberdade, a formação do cidadão da sociedade fundada com o contrato social. Como consequência, a vida social e política é o fim da educação. No entanto, como se verá, essa última tem um dinamismo particular que não assume o paradigma da sociedade, nem sequer da sociedade do contrato. Portanto, a sociedade política não é, na interpretação de Rousseau, o modelo da educação; esta tem a sua própria autonomia. Não podendo apoiar-se na sociedade como paradigma da ação pedagógica, Rousseau identifica a natureza como ponto de referência para a formação do homem.

\section{Breve biografia ${ }^{1}$}

Jean-Jacques Rousseau nasceu em Genebra, no dia 28 de junho de 1712, filho de Susana Bernard e Isaac Rousseau. Com a morte de sua mãe ao nascer e a ausência do pai durante a infância e a adolescência, sua educação primária ficou a cargo de um tio, que o colocou como aprendiz em uma oficina de gravador. Aos 16 anos fugiu de casa e foi confiado aos cuidados de Luisa Eleonora, baronesa de Warens. Nesse mesmo ano foi batizado na Igreja Católica. Nessa época pôde completar

\footnotetext{
${ }^{1}$ Para dados biográficos foram consultadas as seguintes obras: BRONOWSKI, J. Tradicion intelectual de Ocidente: de Leonardo a Hegel. Madrid: Norte y Sur, 1963.; CAMBI, Franco. História da pedagogia. São Paulo: Unesp, 1999.; HIRSCHBERGER, Johannes. Historia de la filosofia II - Edad Moderna y Edad Contemporánea. Barcelona: Herder, 1997.; SALOMON-BAYET, Claire. Jean-Jacques Rousseau. In: CHÂTELET, François. Historia da Filosofia: a filosofia de Galileu a J-J Rousseau. Lisboa: Dom Quixote, 1981; SANZ SANTACRUZ, Víctor. Historia de la filosofía moderna. Pamplona: EUNSA, 1991.
} 
seus estudos de física, química, astronomia, botânica, filosofia e direito, ao mesmo tempo em que exercia a profissão de escrivão.

De 1740 a 1749 exerceu sucessivos trabalhos - preceptor, secretário e músico - sem muito êxito. Nesse intervalo de tempo se estabeleceu em Paris e conheceu Thérèse Levasseur, com quem teve cinco filhos, que jamais chegou a educar. Como se sabe, abandonou-os na roda dos expostos do orfanato "Enfants Trouvés". Nessa mesma cidade, Rousseau teve a oportunidade de travar relações com um grupo de intelectuais, dentre os quais se encontravam Diderot e d'Alembert. Estes, trabalhando nos primórdios da publicação da Enciclopédia, pediram a colaboração de Rousseau com os vocábulos de Música e Economia.

Em 1750, Rousseau apresentou à Academia de Dijon o seu primeiro trabalho de caráter filosófico, o Discours sur les sciences et les arts, com o qual ganhou seu primeiro prêmio. Em 1753 voltou a apresentar à mesma Academia o Discours sur l'origine et les foundaments de l'inégalité parmi les hommes, obtendo, dessa vez, o segundo lugar. $\mathrm{O}$ conteúdo desses discursos incomodou muitos dos participantes do círculo de filósofos que se formavam sob o caráter iluminista, principalmente pelo ataque que faziam ao desenvolvimento da razão. Defendendo suas convicções, Rousseau chegou a romper relações com muitos deles, em especial com Voltaire.

Em 1754 passou uns meses em Genebra, recuperando seus direitos de cidadão ao converter-se ao calvinismo. Em outubro desse mesmo ano retornou a Paris e, nos anos seguintes, publicou a maioria das suas obras. É desse período o artigo a respeito da Economia política para a enciclopédia e Lettre à d'Alembert sur les spetacles ambos publicados em 1758, La nouvelle Héloïse que veio à luz em 1761, Le contrat social e o Émile publicados em 1762. Esse último foi condenado pelas autoridades civis e religiosas de Paris e, desde então, se iniciou um período de grandes fugas e sofrimentos. Com o intento de se defender, Rousseau começou a escrever as suas Confissões. Depois de uma estância breve na Inglaterra, voltou para a França, publicou 
o Dicionário de música e se casou com Thèrése. Viveu pobremente. Posteriormente, escreveu Dialogues de la montagne entre 1775 e 1776 e Réveries du promeneur solitaire entre 1777 e 1778, obras de carácter biográfico.

Ao final de sua vida foi acolhido pelo marquês Estanislau de Girardin, em Ermenonville e, em 2 de julho de 1778, morreu em consequência de uma insolação. Foi enterrado na Ilha dos Choupos, em Ermenonville. Durante a Revolução Francesa, seus restos mortais foram colocados no Panteão, em Paris.

Rousseau é um dos grandes teóricos da Ilustração Francesa, considerado o arauto da Revolução Francesa e o pregador dos direitos do homem. Apesar de sua convivência com muitos filósofos ilustrados, alguns pensadores o têm por anti-iluminista, já que a sua perspectiva emotiva e sensitiva da realidade contrasta fortemente com o racionalismo que prosperava entre os seus contemporâneos. $\mathrm{O}$ pensamento predominante da época considerava o progresso científico-intelectual a chave para o desenvolvimento moral e o exercício da cidadania política. Já Rousseau defendia a simplicidade da natureza e o contrato social como pautas para a vida do homem. Seu pensamento se situa dentro de uma herança idealista, iniciada com Descartes, e reflete sobre o mundo tendo por princípio uma referência notadamente subjetiva.

\section{Discursos filosóficos: reflexão sobre natureza, liberdade e sociedade}

Dentre as primeiras obras de Rousseau, encontram-se algumas de caráter filosófico que marcaram a sua entrada na arena intelectual. Têm, por isso, um significado histórico relevante e constituem o núcleo fundamental do seu pensamento. No Discurso sobre as ciências e as artes (Rousseau, 1999a) e no Discurso sobre a origem e o fundamento das desigualdades entre os homens (Rousseau, 1999a) o autor apresenta uma reflexão antropológica sobre elementos dinamicamente entrelaçados 
na vida do ser humano: a sua natureza peculiar, a sua dimensão livre e a vida em sociedade.

A natureza é o dado primordial, o ponto de partida da sua argumentação. Apesar de Rousseau (1999a) não oferecer uma definição filosófica sobre a natureza humana, a condição natural é amplamente descrita de modo a permitir a apreensão do seu significado: "não é uma empresa leve deslindar o que há de originário e de artificial na natureza atual do homem, e conhecer bem um estado que não existe mais, que provavelmente não existirá jamais, e sobre o qual, entretanto, é necessário ter noções justas para bem avaliar nosso estado presente" (Rousseau, 1999a, p. 44-45).

Observe-se que Rousseau fala da natureza como um estado originário do homem e também como uma ferramenta essencial para compreender o seu estado atual. A sua noção de natureza remonta ao projeto original ou à configuração primeira do homem. Esse dado não tem um valor meramente acessório, pelo contrário, Rousseau o tem por substancial. Considerando, por sua vez, o fato de esse estado já não existir mais, se entrevê a afirmação implícita de uma ruptura ou perda da condição natural. Ao mesmo tempo, aquele estado originário é um instrumento, um aparelho teórico, um ente de razão capaz de auxiliar na compreensão do homem histórico. Rousseau, falando sobre o caráter instrumental da natureza originária, afirma que

Não se devem considerar as pesquisas, em que se pode entrar neste assunto, como verdades históricas, mas somente como raciocínios hipotéticos e condicionais, mais apropriados a esclarecer a natureza das coisas do que a mostrar a verdadeira origem e semelhança àquelas que, todos os dias, fazem nossos físicos sobre a formação do mundo. (Rousseau, 1999a, p. 53).

Portanto, a compreensão que Rousseau oferece da natureza originária não pretende basear-se em dados empíricos, mas se coloca como formulação de hipóteses. Com isso, se veem dois 
aspectos interessantes da proposta de Rousseau. De um lado, que a sua hipótese não está baseada no conhecimento empírico científico: não é a proposição provisória de um conhecimento que poderá ser posteriormente confirmado direta ou indiretamente. A hipótese sobre o significado da natureza originária não está destinada a uma posterior comprovação. Por outro lado, isso mostra que a natureza, para Rousseau, não é um modo de ser e obrar específico do homem, configurador de uma identidade humana. E a prova disso poderia ser que, para ele, o sujeito humano histórico, apesar de ter perdido a condição natural, não deixou de ser homem. $\mathrm{O}$ seu conceito de natureza pode, portanto, ser melhor entendido como um conjunto de raciocínios com os quais ele tenta explicar o projeto original perdido do homem.

$\mathrm{Na}$ construção rousseauniana, o homem no estado natural é um ser desprovido de razão, associal e pacífico, que busca somente a sua sobrevivência. Como conclui Salinas Fortes (1997, p. 38), esse homem tem por "características principais: a vida isolada na abundância; faculdades em existência virtual; ausência de paixões; comportamento aquém do bem e do mal". Tratar-se-ia, portanto, de um ser associal e amoral, que não está inclinado a uma vida comum nem possui uma orientação última para a própria existência.

Rousseau assinala dois princípios daquela vida natural: um que interessa ao bem-estar e à conservação do homem (amor de si), e outro que inspira compaixão diante do sofrimento alheio (piedade). Ambos os princípios são anteriores à razão e distanciam-se de qualquer princípio de sociabilidade, moralidade ou racionalidade. Toda essa descrição - associabilidade, amoralidade, ausência de paixões, instinto de conservação e reconhecimento do sofrimento alheio - configura o que ele chama de bondade natural do homem. Rousseau não usa o termo bondade como qualificação do indivíduo que age em consonância com o bem, mas como passividade que impede que da natureza possa surgir o mal.

Entretanto, Rousseau afirma que o homem não é um animal como os demais, já que dispõe de liberdade, a qual se identifica 
conceitualmente com vontade (Barros, 1963, p. 20). A liberdade confere ao homem a capacidade de aperfeiçoar-se e esse é o fator determinantemente humano. Rousseau introduz uma dicotomia entre razão e vontade, porque não concebe o querer voluntário - livre - como o desejo de um bem conhecido e orientado pelo conhecimento racional. Ao recusar o papel da razão, a vontade passa a ser a característica peculiar do ser humano, ligada mais aos sentimentos.

O trajeto feito até aqui, que explica qual era a situação inicial do homem, não justifica a perda daquele estado de natureza original. Segundo Rousseau (1999a, p. 84), a causa do mal não emana da natureza do homem, mas de algo extrínseco a ela:

Depois de ter mostrado que a perfectibilidade, as virtudes sociais e as outras faculdades que o homem natural recebera potencialmente jamais poderão desenvolver-se por si próprias, pois para isso necessitam do concurso fortuito de inúmeras causas estranhas, que nunca poderiam surgir e sem as quais ele teria permanecido eternamente em sua condição primitiva, resta-me considerar e aproximar os vários acasos que puderam aperfeiçoar a razão humana, deteriorando a espécie, tornar mau um ser ao transformá-lo em ser social e, partindo de tão longe, trazer enfim o homem e o mundo ao ponto em que os conhecemos.

$\mathrm{O}$ autor sustenta que dentre as causas estranhas que provocaram a degeneração do estado natural está a necessidade de sobreviver, o desenvolvimento da linguagem e o estabelecimento da propriedade privada, fatores esses que levaram à configuração de um modo de agir distinto da forma original de ser. Rousseau não se pergunta como esses elementos extrínsecos puderam modificar a natureza sem que houvesse nela uma disposição, pelo menos potencial, à recepção desse influxo. $\mathrm{O}$ que ele faz é elogiar ironicamente os progressos que a mente humana proporcionou aos homens - o conhecimento de si, das suas próprias capacidades, da realidade externa -, para propor depois que as ciências 
e as artes nada mais fizeram senão ocultar a realidade da escravidão. $\mathrm{Na}$ sua interpretação, as virtudes que o homem acreditava possuir eram só aparências que escondiam, sob a capa da polidez e do decoro, a realidade da sua corrupção. Como interpreta Starobinski (1991, p. 17), "que ser e parecer sejam diversos, que um 'véu' dissimule os verdadeiros sentimentos, esse é o escândalo inicial com que Rousseau se choca, esse é o dado inaceitável de que buscará a explicação e a causa, essa é a infelicidade de que deseja ser libertado".

Rousseau reconhece que, uma vez iniciada a sociedade e no estágio em que se encontra, é impossível retornar ao estado natural sem incorrer em um mal maior. Portanto, é preciso cultivar qualidades que são próprias da vida em sociedade e distintas daquelas que seriam cultivadas no estado original. Tirando as consequências dessa ideia, Boto (2002, p. 326-327) afirma que se dá uma substituição da bondade originária pela virtude moral:

Assim pode ser demarcada a distinção primordial, no pensamento rousseauniano, entre bondade e virtude. A primeira era um dado de natureza que tinha a ver com a simpatia, com a compaixão, com a piedade, ou a capacidade de se reconhecer no infortúnio do outro. A virtude, entretanto, só se poderia conceber mediante critérios atinentes à moralidade. Ora, a moralidade supõe o pacto, convenção social.

Com efeito, no Discurso sobre as ciências e as artes e no Discurso sobre a origem e os fundamentos da desigualdade entre os homens, Rousseau (1999a) abre a sua proposta antropológica da busca de um remédio para o homem histórico, que se alcançará por meio do contrato social - em nível coletivo - e da educação em nível individual.

\section{O Contrato Social: sociedade, liberdade civil e pacto social}

Uma vez que pressupõe um estado natural original no qual os homens são livres e independentes entre si, Rousseau se vê obrigado 
a eleger entre condenar e combater toda forma de sociedade, ou bem justificar os vínculos sociais. A primeira possibilidade é eliminada, pois ele sustenta que, apesar da artificiosidade da realidade social, o homem se encontra em um estado tal que já não pode prescindir dela sem causar um mal maior a si mesmo. Rousseau pensa que não seria conveniente eliminar toda forma social instituída na vida civil, porque vê essa ordenação como o fundamento irrevogável de todos os direitos. Esses últimos, que não são concebidos por ele como direitos fundados na identidade comum dos homens, constituem, no entanto, o ordenamento necessário para suprir as desigualdades naturais que se dão entre os indivíduos.

Se a sociedade não pode ser condenada e abolida, tem de ser justificada de algum modo. Com o fundamento legitimador, Rousseau encontra a liberdade humana, considerada em um duplo aspecto. Ele considera que, em primeiro lugar, a liberdade indica autonomia, possibilidade de realização de atos conforme os desejos próprios do agente. Desse postulado, tira a consequência de que a primeira lei do homem é a manutenção da vida com a finalidade de se projetar, de se tornar autônomo, senhor de si.

Esta liberdade comum é uma consequência da natureza do homem. Sua primeira lei consiste em zelar pela própria conservação, seus primeiros cuidados são aqueles que deve a si mesmo e, assim que alcança a idade da razão, sendo o único juiz dos meios adequados para conservar-se, torna-se, por isso, senhor de si. (Rousseau, 1999c, p. 55).

Em segundo lugar, concebe a liberdade como ausência de condicionamentos externos na realização de atos autônomos. Esta recebe o nome de liberdade civil, porque se dá somente em um ambiente de vida comum regulada por um pacto social. Rousseau considera livre, portanto, o homem que é ao mesmo tempo um ser autônomo e um cidadão. Por isso, não basta a liberdade no primeiro 
sentido, como domínio de si. O homem necessita da liberdade civil, que lhe garante o direito de obedecer a todos obedecendo a si mesmo (Rousseau, 1999c, p. 77-78).

Sem a garantia da liberdade, entendida nesse segundo sentido, o estado do homem seria o de escravidão. A liberdade de autonomia depende, portanto, da liberdade civil. Mas como fazer para que a vida comum não obstaculize a autonomia individual? Essa meta requer um marco seguro de proteção do indivíduo que Rousseau (1999c, p. 61) encontra nas convenções: "visto que homem algum tem autoridade natural sobre seus semelhantes e que a força não produz nenhum direito, só restam as convenções como base de toda a autoridade legítima existente entre os homens". O ato supremo de estabelecimento das convenções é o que Rousseau chama de pacto ou de contrato social.

Ele considera que o contrato social não designa um ato de submissão por meio do qual o povo cede sua liberdade e seus direitos a um governante em troca da pacífica convivência. Semelhante pacto seria, para Rousseau, forçosamente ilegítimo e nulo: geraria um regime de despotismo e de sujeição, nunca uma ordem política conforme a liberdade e igualdade originárias do homem.

Renunciar à liberdade é renunciar à qualidade de homem, aos direitos de humanidade, e aos próprios deveres. Não há recompensa possível para quem a tudo renuncia. Tal renúncia não se compadece com a natureza do homem, e destituir-se voluntariamente de toda e qualquer liberdade equivale a excluir a moralidade de suas ações. (Rousseau, 1999c, p. 62).

O pacto ou o contrato social deve ser entendido, segundo Rousseau, como a transferência coletiva dos direitos individuais, não em favor de um ou vários governantes, mas em favor de toda a comunidade constituída mediante um contrato. A essência desse contrato, ou melhor, a explanação da sua cláusula seria: "cada um de nós põe em comum toda a sua pessoa e todo o seu poder sob a direção 
suprema da vontade geral, e recebemos, enquanto corpo, cada membro como parte indivisível do todo" (Rousseau, 1999c, p. 71).

$\mathrm{Na}$ interpretação rousseauniana, com o pacto social instaurase a ruptura mediante a qual os homens passam do estado natural ao estado civil de direito. Com isso, sustenta, a justiça substitui o instinto; a voz do dever, o impulso físico; o direito, o apetite; e o indivíduo que antes olhava apenas a si mesmo, se vê obrigado a consultar a razão antes de prestar ouvido às suas inclinações, fazendo com que seus atos adquiram a moralidade de que antes careciam (Rousseau, 1999c, p. 77). Fica claro que, nessa conclusão, Rousseau não se refere à moralidade como valoração dos atos conforme um princípio do bem humano que transcenda a razão, mas sim aos termos da racionalidade moderna, na qual o critério de determinação da justiça, do dever e do direito é só imanente: a razão mesma.

Com o estabelecimento do pacto social, o homem perde sua liberdade natural e o direito ilimitado a quanto deseja, mas ganha a liberdade civil circunscrita pela vontade geral. Por isso, Rousseau concebe a vontade geral como a expressão do comum interesse de viver em sociedade, fator constitutivo do vínculo social e critério exclusivo do governo da comunidade. $\mathrm{O}$ poder que antes estava na vontade de cada indivíduo reside, agora, em virtude do contrato, na vontade da comunidade inteira, na vontade geral. Ele entende que assim os indivíduos conservam seus interesses particulares ao mesmo tempo em que permanecem súditos; têm, como consequência, o dever moral de adequar sua vontade particular à vontade geral da comunidade soberana, de cujo poder legislativo eles mesmos participam.

Depois de afirmar a essência da vontade geral e a sua importância no contexto do pacto social, convém ressaltar outra consequência do contrato social que está na base do sistema sócio-político rousseau

O pacto fundamental, em lugar de destruir a igualdade natural, pelo contrário substitui por uma igualdade moral e legítima aquilo que a natureza poderia trazer de desigualdade física entre os homens, que, 
podendo ser desiguais na força ou no gênio, todos se tornam iguais por convenção e direito. (Rousseau, 1999c, p. 81).

O contrato social, segundo Rousseau, está orientado, portanto, para a restauração da igualdade entre os homens, perdida com a sociedade.

\section{Emílio: educação natural, autoridade e infância}

A instauração da sociedade do contrato não se dá por meio de uma reforma ou evolução espontânea no interior da própria sociedade civil. Faz-se necessária a intervenção de um elemento exterior a ela, algo capaz de romper o ciclo vicioso da corrupção humana e de estabelecer novas relações sociais. A única possibilidade encontrada por Rousseau para ativar esse processo é a educação do homem segundo os parâmetros da sua natureza original. Somente assim o homem pode manter sua integridade natural e estabelecer verdadeiramente o pacto social. Na sua obra Emílio, Rousseau se propõe a estabelecer as bases e as condições dessa formação do homem.

É preciso ter em conta, entretanto, como bem reconhece Barros (1963, p. 59), que essa obra não é "um manual de pedagogia prática”. Rousseau não pretende que as suas observações de caráter prático adquiram um rigor científico, mas, sim, que sejam suporte para o construto teórico que é a educação de Emílio. Como afirma Boto (2002, p. 344), "Emílio teria sido, para Rousseau, uma alternativa; a utopia de formação do homem virtuoso no seio da sociedade civil corrompida”.

Considerando que a natureza é boa, Rousseau concebe um ideal educativo que assume como supremo critério pedagógico o desenvolvimento imanente da natureza. Segui-la; adequar-se a ela; respeitar seus estados evolutivos sem pretender antecipá-los; não introduzir nela o que lhe é alheio nem o que - sem lhe ser estranho é, todavia, prematuro; não ensinar o que em um dado momento não 
corresponde a um interesse vivo: essas são as regras que ele reconhece na atividade educativa. De acordo com a sua visão, a educação deve proteger, potenciar e enriquecer a espontaneidade natural, tratar a criança como criança e não como um adulto potencial. Por isso, a descrição da educação de Emílio em cada idade tem por finalidade instaurar um sentimento de reconhecimento da infância.

A ideia de infância, tal como a considera Rousseau, quer contrastar o pensamento comum da sua época. Por um lado, certa visão religiosa considerava a criança um ser frágil, completamente vulnerável ao mal e ao pecado, de modo que se via necessário afastá-la do mundo com o intuito de preservá-la dos males sociais. Por outro lado, devido a um processo de nuclearização da família e de privatização dos costumes, a criança também era vista como um elo de continuidade econômica e como solução de perpetuação da linhagem familiar. Como consequência, a sua existência era concebida e integrada no grupo familiar sob o serviço dessa instituição. A infância estava, portanto, funcionalizada à vida adulta e dela recebia o seu valor.

Rousseau (1999b, p. 86), por sua vez, sustenta que "a natureza quer que as crianças sejam crianças antes de serem homens. [...] A infância têm maneiras de ver, de pensar e de sentir que lhe são próprias". No conjunto das suas ideias, a infância corresponde à fase original e primigênia da humanidade: Emílio representa o homem de natureza, isto é, o homem no estado natural. Nessa perspectiva, uma educação que pretenda preservá-lo dos males sociais deve dar-se em um ambiente de isolamento e vigilância onde toda a ação pedagógica do preceptor esteja orientada para esse mesmo fim. No caso do Emílio imaginado por Rousseau, tudo isso é facilitado pelo fato de ele ser órfão, sem problemas econômicos e educado em ambiente rural.

Dado que a tarefa educativa exige uma consciência sempre atual das necessidades do aluno e do que lhe corresponde segundo sua natureza, o preceptor é, para Rousseau, a figura mais relevante na educação de Emílio. A relação entre educador e aluno deve caracterizarse pelo respeito e pela confiança mútua, constituindo-se pela premissa 
de que a educação se dirige ao benefício pessoal do educando. Por isso, Rousseau observa que a autoridade do preceptor não é conquistada na base da força, mas, sim, justificada legitimamente pela garantia do seguimento da natureza. Somente nessas condições o discípulo the concede autoridade e reconhece o seu exercício (Cerizara, 1990, p. 56).

A prática da autoridade é sempre um ato diretivo por parte do preceptor, mesmo quando se trata de intervenções não evidentes. De fato, Rousseau esclarece que a ação do preceptor muitas vezes é controlar indiretamente o ambiente do educando, suas experiências, suas companhias, seus jogos e todas as suas atividades. Aqui se põe de manifesto - como afirma Victoria Camps (1996, p. 106) - que não há neutralidade na educação, uma vez que educar sempre é formar valores: "Se educar é dirigir, formar o caráter ou a personalidade, levar o indivíduo a uma determinada direção, a educação não pode, nem deve ser neutra”. Rousseau (1999b), com efeito, não é neutral, pois apresenta a ação do preceptor, também quando indireta, como a via para a preservação da bondade da criança. $O$ que Rousseau não põe em evidência é uma proposta sobre o modo de formar o preceptor, que permanece, assim, um personagem imaginário como o próprio Emílio. Enquanto o educando conta com o preceptor como referência segura para se desenvolver, este carece de um guia para reconhecer os elementos do estado de natureza ou distinguir, dentre os fatores externos, aqueles que favorecem a bondade natural de Emílio.

O preceptor, na teoria rousseauniana, é alguém já capacitado para guiar as diversas educações que acompanham o desenvolvimento natural de Emílio, que são: a educação negativa, a educação dos sentidos, a exploração do ambiente, a aquisição do sentido do útil, a observação e a execução do trabalho, a educação moral e política e as viagens de instrução. Mais do que explicar cada uma, neste artigo interessa ressaltar que em todos esses processos a maturidade da infância é o único modelo da educação. Rousseau inverte os paradigmas: o fim da educação durante a infância já não é conduzir à idade adulta, mas incrementar a própria infância. 
Essa ação do preceptor prepararia Emílio para o seu segundo nascimento. Depois de nascer para a existência, resta nascer para a vida. Rousseau entende que o homem passa por dois processos de maturação, o primeiro é o biológico e o segundo, proveniente da aquisição da razão, é o que leva à consciência de si, à formação da individualidade e à compreensão do próprio corpo. Nesse segundo processo se desenvolve a capacidade humana de perfectibilidade, com a qual começa a educação moral e se desenvolve o reconhecimento dos demais homens, dando início à educação política.

Uma vez concluída a educação de Emílio, o preceptor deve afastar-se para dar lugar à autonomia, à liberdade. Rousseau considera que Emílio, formado segundo os parâmetros da natureza, mantém vivos seus atributos naturais e, ao mesmo tempo, está preparado para conviver em sociedade. Emílio é o indivíduo que será capaz de instaurar a sociedade do contrato.

\section{Considerações a respeito das categorias político-filosóficas}

Rousseau assume uma postura de arauto inflamado do romantismo e é um grande contestador do seu tempo e dos progressos da razão. Apela principalmente para a retórica como recurso persuasivo, mais do que à lógica racional - elemento que muitas vezes é objeto de crítica dos seus opositores.De acordo com Fazio (1998,p.129), as críticas se devem mais especificamente à "dispersão temática e à variedade estilística de seus escritos”.Para Rousseau,o ponto de partida da reflexão não é a realidade objetiva e o instrumento de compreensão do mundo não é a razão. $\mathrm{O}$ seu idealismo parte de uma perspectiva subjetiva - a intuição pessoal - e da sensibilidade para entender o que o circunda. Como consequência, a teoria rousseauniana é um esforço para manter uma coerência interna e conciliar as possíveis incompatibilidades entre o mundo externo e a sua visão pessoal da realidade. Essas dificuldades se espelham bem na observação feita por Roque Spencer Maciel de Barros ao estudar a noção de natureza em Rousseau (1963, p. 19): 
Paradoxalmente, entretanto -, e é difícil tratar de Rousseau sem enfrentar paradoxos - essa concepção do homem que garante a coerência do pensamento rousseauniano é, ela própria, o produto de uma superposição de formas contraditórias de encarar os problemas centrais da filosofia. Coexistem em Rousseau o empirismo e o idealismo ético, a epistemologia sensualista e a concepção moral do mundo.

Partindo desses pressupostos, é fácil compreender que a decisão de Rousseau de encontrar na educação e no pacto social um remédio para aliviar os males da sociedade está longe de ser uma proposta prática de correção do que ele concebe como a queda humana. Partindo da ideia de que o homem civil perdeu para sempre o estado natural e jamais poderá reconquistá-lo, o seu projeto de salvação do homem é só uma possibilidade de sobrevivência do indivíduo dentro da sociedade corrompida e um esboço das condições para a formação do que ele chama de sociedade do contrato. Tudo isso, no entanto, não se apresenta como uma garantia da viabilidade da sua proposta (Barros, 1963, p. 17).

Nas obras Discurso sobre as ciências e as artes e Discurso sobre a origem e os fundamentos da desigualdade entre os homens, Rousseau (1999a) sinaliza o declínio moral da humanidade por conta do progresso científico e tecnológico. Tudo indica um completo desastre para o homem na passagem do estado natural para o estado social. Entretanto, como interpreta Franklin de Matos (apud Fortes 1997), há, na teoria de Rousseau, uma possibilidade de remediar o mal da duplicidade do homem:

o mal não é irremediável. Em primeiro lugar, esta passagem, tal como se deu, não tem nada de necessário, o que abre a possibilidade para uma reforma do mundo existente; em seguida, se a passagem implica perda da plenitude original, ela também pode significar um ganho inestimável: a possibilidade de aprender a natureza como Ordem (Matos apud Fortes, 1997, p. 9). 
Aprender a natureza como "Ordem" significaria, para Rousseau, colocá-la como centro do seu pensamento filosófico e como eixo central de sua antropologia. A natureza é, assim, a origem e o fim do homem. Eis o grande desafio proposto nas obras de Rousseau, sejam elas de caráter filosófico, pedagógico, político ou literário: a tentativa de retorno ao homem natural, mesmo sabendo que jamais se chega a alcançá-lo; a preservação do amor de si e da piedade, em um meio em que predomina o amor próprio egoísta e a impiedade; a formação da integridade pessoal e a aproximação com os princípios naturais vivendo em um estado contra-natura; a manutenção da unidade do homem perante o triste panorama da "duplicidade do homem existente - como assinala Salinas Fortes (1997, p. 9) -, a contradição entre a sua realidade e seu modo de parecer, o seu fenômeno".

Rousseau considera que o estado civil, isto é, a condição social do homem histórico, além de alterar a estrutura e a unidade interna do homem de natureza, provoca uma revolução no valor de cada indivíduo. Assim o explica Gilda Naécia Maciel de Barros (1996), afirmando que em Rousseau o homem originário é um todo em si, e possui um valor absoluto porque não depende do reconhecimento dos demais; já o homem social possui um valor relativo ao todo do qual faz parte. Nessa linha, a autora prenuncia um aspecto fundamental da teoria pedagógica rousseauniana: a tentativa de conciliação entre a educação pautada pela natureza e a convivência no ambiente social. Rousseau considera a natureza como a verdadeira referência originária do homem, como o seu projeto. A sociedade não pode, portanto, como a natureza, fornecer o ser ao homem, mas somente o parecer; não pode conferir-lhe um valor absoluto, apenas um valor relativo (Barros, 1996). Essa interpretação recolhe o fato de que na perspectiva de Rousseau não há conciliação possível entre o valor ou a dignidade que o indivíduo adquire no ambiente social mediante as suas ações e a dignidade essencial que ele tem como ser humano.

No entanto, antes de prosseguir com essa reflexão, é preciso entender que Rousseau pensa a natureza de forma independente da 
história, como um pressuposto dela (Barros, 1996, p. 191). Carlota Boto (2002, p. 318) esclarece a ideia de história e a sua relação com o conceito de natureza com a seguinte observação:

A história que Rousseau constrói é outra [...]. Como máscaras e representações teriam se tornado inerentes à própria idéia de civilização, Rousseau pretende, em seus escritos, recuperar a origem perdida; chegar ao ponto primeiro onde a própria noção do tempo teria sido inventada. Essa retomada dos primórdios requereria, porém, uma suposição de possibilidades: uma outra história - sem máscaras para explicar o gênero humano e para contar do desenvolvimento da vida individual em suas diversas etapas. No primeiro caso, tratava-se da política; no segundo, da pedagogia.

O homem do estado de natureza - a origem perdida à que se refere Boto (2002) - não é, portanto, um ser histórico, mas um arquétipo, com base no qual Rousseau elabora sua teoria da bondade original. Não tendo existência real, a natureza funciona como um recurso lógico-dedutivo para justificar suas teorias políticas e pedagógicas. Também Locke e Hobbes utilizaram o estado de natureza como uma construção com finalidade semelhante. Isso manifesta mais claramente que Rousseau é tributário de uma herança moderna que remonta à tradição filosófica cartesiana, "radicalmente a-histórica" - como reconhece Boto, citando, por sua vez, Cassirer (Boto, 2002, p. 318) - e que projeta a natureza humana como uma utopia, um ideal imutável.

No campo da pedagogia, Rousseau também precisará apoiarse na figura abstrata de Emílio, criança idealizada que receberá uma educação destinada a preservar ao máximo possível as qualidades naturais do ser humano em estado natural. Trata-se de desenvolver a mesma forma de pensamento tanto no nível filogênico, ou seja, referente à espécie, quanto no nível ontogênico, individual. $\mathrm{O}$ mesmo processo de desnaturação que sofre o selvagem rousseauniano ao longo da sua socialização ocorre com a criança. 
Desnaturar não significa, contudo, ignorar a natureza e atentar contra ela, mas transformar o homem natural em homem social. Olgária Matos (1985, p. 53) define a desnaturação como "obra da contra-natureza, (que) assinala o momento da perda de independência do indivíduo, quando um homem precisou do socorro do outro para a sua sobrevivência”. Em outros termos, a expressão desnaturação indica, em Rousseau, socialização. Gilda de Barros (1996) interpreta-a afirmando que socializar pode ter dupla conotação. Por um lado está a degradação, a perda da bondade originária; por outro, a preservação e a transformação do homem que se encontra em um estado degradado: "As boas instituições sociais são aquelas que melhor sabem desnaturar o homem, tirar-lhe sua existência absoluta para lhe dar uma relativa, e transportar o eu para a unidade comum" (Rousseau apud Barros, 1996, p. 182). No caso do homem natural, a instituição propícia para o processo de desnaturação foi a familiar; no caso particular de cada indivíduo, é a educação.

A desnaturação não é, por assim dizer, no parecer de Rousseau, o grande mal do homem, antes o é a sociedade degradada e o domínio do amor próprio. A origem do mal não se encontra em Deus nem na natureza humana, mas na sociedade. Entretanto, se essa transformação significou uma grande perda para o homem natural e a introdução do mal, ela também significou a possibilidade de elevação da alma, a possibilidade de ganhar outro panorama vital. O homem, ao perder seu estado de natureza, tornou-se capaz de ser moral. E a moralidade é originária da natureza, a realização da liberdade humana, a possibilidade de enobrecimento dos sentidos no âmbito da sociedade do contrato delineada por Rousseau.

Também a educação que ele concebe é necessária para a regeneração do estado humano. $\mathrm{O}$ objetivo desse processo é possibilitar ao indivíduo conviver na sociedade corrompida sem, no entanto, se desviar dessa finalidade nem daqueles princípios naturais que são o amor de si e a piedade. Nesse sentido, a função da educação, segundo Rousseau, é preservar o homem da corrupção 
do amor-próprio, capacitá-lo para agir conforme uma moralidade reconhecida nas exigências do pacto social. Desse modo, o pacto social regenera a espécie partindo da sua fonte de imoralidade - a sociedade corrompida.

Abre-se, assim, o horizonte para a compreensão da educação proposta por Rousseau: a libertação das convenções sociais caducas e a recondução à simplicidade e à singeleza da natureza (Cassirer, 1999, p. 114).

\section{O pensamento pedagógico rousseauniano: considerações finais}

O processo educativo rousseauniano se posiciona na perspectiva de educar o homem segundo os parâmetros da natureza para que ele possa manter-se íntegro, o que significa a indivisibilidade da natureza, a superação da queda ou da ruptura. A integridade e o isolamento do homem natural configuram, assim, o modelo fundamental da educação de Emílio.

Nascido para viver livre em uma sociedade corrompida, não resta nada mais a Emílio do que viver solitariamente na vida social. Sua convivência com os demais homens traz-lhe o peso da desgraça da queda. Salinas Fortes (1997, p. 108), reconhecendo a dicotomia rousseauniana entre natureza e sociedade resume a convivência social nos seguintes termos:

Todo o problema da coexistência entre indivíduos distintos está em que há necessariamente uma distância entre a instância do coletivo e a instância do individual. [...] Por outras palavras, para viver em sociedade, os indivíduos devem viver como se não fossem meramente indivíduos, como se fossem suportes de uma realidade que os ultrapassa.

A distância que Rousseau identifica entre a instância coletiva e a individual tem caráter de oposição fundamental, em concordância 
com a sua interpretação da condição natural do homem. Nas palavras de Spaemann (2009, p. 127), o homem natural rousseauniano "não é preordenado à sua determinação cultural por uma necessidade teleológica interna. A transformação cultural que faz do homem somente um ser histórico é um destino exterior contingente”.

Uma vez afirmada a oposição entre natureza e sociedade, Rousseau propõe uma reflexão sobre a educação na qual, transcendendo o menino Emílio, seja possível contemplar ao mesmo tempo a humanidade e suas possibilidades de não sucumbir à corrupção. Carlota Boto (2002, p. 344) enfatiza que

Emílio, teria sido, para Rousseau, uma alternativa; a utopia da formação do homem virtuoso no seio da sociedade civil. Sendo assim, a formação do menino não ocorrerá na sociedade do novo contrato, o que talvez explique - em princípio - o rigoroso isolamento a que o educador/ tutor submete seu discípulo durante os primeiros anos de vida.

Se só o homem livre e autônomo é capaz de manter a sua integridade na sociedade corrompida, como defende Rousseau, a educação deve ser educar para a liberdade. Emílio, portanto, educado para representar em si a totalidade espiritual, é guiado ao longo de seu processo educativo por uma concepção de liberdade que - como afirma o próprio Rousseau - faz parte de sua natureza, ou seja, é o seu desenvolvimento livre. Mas a liberdade a que o homem naturalmente está submetido não se identifica com um poder absoluto, pois encontra como limites as prescrições da lei moral inscrita no seu próprio coração (Rousseau, 1999b, p. 47). A fórmula "lei moral inscrita no coração" é uma expressão retórica, que Rousseau não vincula à capacidade humana de conhecer os princípios (lei moral) que realizam a verdade e o bem próprio da sua condição de sujeito humano. Em vez disso, a lei moral se encontra nas convenções próprias da convivência social; o homem seria livre quando voluntariamente se decidisse a obedecê-las e a vencer os vícios enganosos do mundo. Porém, exaltar a excelência 
da liberdade significa, em Rousseau, voltar a tocar a miséria da queda, reconhecer a condição humana em sua mais cruel realidade. Starobinski (1971, p. 66), comentando sobre isso, afirma:

Então, no momento em que Rousseau propõe-se a resistir à mentira do mundo, ele se coloca na necessidade de resistir a si mesmo. A exigência da virtude, em nome da qual ele se opõe a uma sociedade perversa e mascarada, nele cria a consciência de uma divisão interna, de uma falta de unidade. Ser-lhe-á forçoso constatar a diferença que existe entre a facilidade do impulso imediato e a tensão do esforço virtuoso.

O esclarecimento de Starobinski (1971) realça o significado de moralidade em Rousseau. Trata-se de uma ordenação às exigências da vida em sociedade, do contrato social. Por isso, moralidade não deve ser lida em relação a um bem transcendente à sociedade, que seja critério de valor - bondade ou maldade - das ações humanas. Nesse mesmo sentido, a virtude, em Rousseau, é considerada como uma referência externa que contrasta com os impulsos interiores do homem corrompido; o homem virtuoso submete os seus atos ao dever social. Não se trata, portanto, da virtude entendida como hábito operativo, critério interior pelo qual os atos livres realizam o bem pessoal.

À educação nada mais resta, segundo Rousseau, senão ter como propósito a formação da liberdade entendida como a capacidade de autodomínio dirigido à convivência social. Carlota Boto (2002, p. 345), dissertando sobre a educação de Emílio, conclui que esta "não supunha ser, tampouco, uma educação em liberdade. Seria, mais provavelmente, um educar da liberdade; ou para a liberdade". Nesse sentido, não é possível considerar que a educação de Emílio pudesse proporcionarlhe o uso de sua liberdade para a satisfação dos gostos pessoais ou para estabelecer as condições de sua relação com o preceptor. Emílio não se autodirige ao bem que conhece e ama, mas segue os impulsos espontâneos que o preceptor identifica como sendo os restos do homem natural já não existente. 
Muito embora algumas leituras de Emílio tenham procurado na obra fundamentos que justificassem a liberdade do aluno como meio e condição da educação, o caráter diretivo do preceptor manifesta-se claramente por meio da descrição do processo educativo, bem como por meio do sentido imperativo dos verbos que Rousseau põe na boca do preceptor.

Maria de Fátima S. Francisco (1999, p. 113), ao falar dessa relação pedagógica, classifica-a como um "pacto pedagógico", comparando-o ao pacto político que Rousseau propõe em $\mathrm{O}$ contrato social. Nele, ambas as partes, preceptor e aluno, comprometer-se-iam por meio de deveres mútuos pelos quais teriam garantidos seus direitos. No entanto, observa-se que o processo pedagógico é conduzido pelo preceptor de Emílio ao longo de toda a sua duração. O seu controle chega inclusive a abarcar as circunstâncias e condições da relação pedagógica, de modo que se torna evidente a submissão do discípulo ao preceptor. A marca característica da autoridade na relação já está posta de antemão na proposta pedagógica. Rousseau reafirma uma relação desigual entre ambos, excluindo a possibilidade de qualquer contrato pedagógico. O que legitima a autoridade do preceptor não é a convenção, mas a referência à natureza. Assim, a questão da autoridade é dada a priori: o preceptor só pode ser mestre de outro, porque antes é mestre de si mesmo.

Como já ficou dito, Rousseau não se detém a explicar o processo de formação do preceptor. Agora basta sublinhar que, assim como Emílio serve como modelo e caminho para o homem do contrato social, a sua formação exige que o preceptor esteja capacitado para conduzi-lo a essa meta; e o modo em que um homem pode sair da situação de corrupção e tornar-se mestre de si para poder ser mestre de outros é um aspecto da teoria rousseauniana que parece estar incompleto.

Deve-se reconhecer que a defesa da autoridade do preceptor não supõe, conforme Rousseau, uma oposição radical ao reconhecimento da condição infantil. De fato, ele defende claramente a criança no 
Livro II do Emílio: "falando primeiramente às crianças de seus deveres e nunca de seus direitos, começam por lhes dizer o contrário do que é preciso, o que elas não são capazes de entender e não lhes pode interessar" (Rousseau, 1999b, p. 97-98). Nessa linha, Roque Maciel de Barros (1963, p. 68) atesta a consideração da infância como uma das inovações do pensamento rousseauniano: "a infância há de ser entendida em si mesma e essa descoberta da especificidade da infância não é das menores da pedagogia rousseauniana”.

Rousseau assemelha a natureza infantilà natureza do homem nas suas origens: sustenta que ambos não possuem percepção racional, mas sensorial, e encontram-se isentos de moralidade, porque desconhecem a condição de corrupção e malícia social. Por esse mesmo motivo - a fragilidade essencial -, se vê justificada a autoridade do preceptor como guia da educação e guardião da inocência e dos atributos de natureza na criança. A ideia de Rousseau é que, para aprender a ser livre, o discípulo precisa submeter-se a um curioso paradoxo: ser dirigido por outrem. Consequentemente, a autoridade do preceptor, em Emílio, é, de acordo com Maria de Fátima Simões Francisco (1999, p. 108), um "poder que se exerce não em benefício daquele que o exerce, mas em benefício daquele que se submete a ele".

A natureza de Emílio durante a infância - tal como a do homem natural - deve ser preservada dos males sociais antes de poder ser moralizada. Esse é o significado e a justificativa da educação negativa proposta por Rousseau: a criança, dentro das suas capacidades infantis, não está preparada para sobreviver ao mal. Deve ser antes preservada dele até que a maturação de seus sentimentos, paixões e razão a conduzam pelas veredas da moralidade.

Ao estabelecer as bases da educação em cada fase da vida, tendo em vista a formação da liberdade civil e a felicidade do discípulo, Rousseau determina que a educação moral e a educação política constituam o final do processo educativo de Emílio, quando este já se encontra entre 15 e 20 anos. Com o desenvolvimento gradativo da natureza, o preceptor conduz o discípulo ao reconhecimento do outro 
e da sociedade por meio da propriedade e das relações de trabalho entre os homens.

Uma vez compreendida a natureza da relação social - derivada "da fraqueza comum à condição de homem" (Boto, 2002b, p. 53) -, a educação moral e política assume dois propósitos. O primeiro é "atualizar as potencialidades éticas da natureza humana, elevando-a ao plano da moralidade" (Barros, 1963, p. 64). O segundo consiste em formar o cidadão que esteja, como diz Rousseau (1999b, p. 646), "versado em todas as matérias do governo, dos costumes públicos e das máximas de Estados de toda a espécie”. O projeto da educação política não é outro senão dar conhecimento aos homens da melhor forma de governo para estabelecer os direitos da humanidade.

A teoria rousseauniana, portanto, quer transcender as circunstâncias sócio-históricas do momento em que ele viveu. Em seu contexto geral, parece clara a intenção de oferecer, por intermédio da educação, os elementos necessários ao estabelecimento da sociedade do contrato em uma dimensão individual. A educação seria então uma tentativa de recuperar em cada indivíduo a referência da natureza para instaurar a sociedade do contrato.

\section{Referências}

BARROS, Roque Spencer Maciel de. Meditação sobre Rousseau. Sep. do vol. 6. USP: Centro Regional de Pesquisas Educacionais, 1963.

BARROS, Gilda Naécia Maciel de. Platão, Rousseau e o Estado total. São Paulo: Queiroz, 1996.

BOTO, Carlota. História, verdade e virtude em Rousseau: pacto político e ética pedagógica. Revista de História das Idéias: história e verdade(s), Coimbra, v. 23, p. 317-363, 2002a.

BOTO, Carlota. O desencantamento da criança: entre a Renascença e o Século das Luzes. In: FREITAS, M. C.; KUHLMANN Jr., M. (Org.). Os intelectuais na história da infância. São Paulo: Cortez, 2002b. p. 11-60.

BRONOWSKI, J. Tradición intelectual de Occidente: de Leonardo a Hegel. Madrid: Norte y Sur, 1963. 
CAMBI, Franco. História da pedagogia. São Paulo: Unesp, 1999.

CAMPS, Victoria. La buena educación. In: .Virtudes públicas. Madrid: Espasa Calpe, 1996.

CASSIRER, Ernest. A questão Jean-Jacques Rousseau. São Paulo: Editora UNESP, 1999.

CASTRO, Aline H. I. Educação, cultura e poder na obra de Georges Snyders: rastros e rumos da alegria na escola. 2004. 194 f. Dissertação (Mestrado em Educação Escolas) - Faculdade de Ciências e Letras, Universidade Estadual de São Paulo, Araraquara, 2004.

CERIZARA, Ana Beatriz. Rousseau e a educação na infância. São Paulo: Scipione, 1990.

CHAUÍ, Marilena de Souza. Rousseau: vida e obra. In: ROUSSEAU, Jean Jacques. Do contrato social: ensaio sobre a origem das línguas. São Paulo: Nova Cultural, 1987.p. VI-XXI. (Coleção Os Pensadores).

FAZIO, Mariano. Due rivoluzionari: F. de Vitoria e J.-J. Rousseau. Roma: Armando, 1998.

FORTES, Luis R. S. Paradoxo do espetáculo: política e poética em Rousseau. São Paulo: Discurso, 1997.

FRANCISCO, Maria de Fátima Simões. Autoridade e contrato pedagógico em Rousseau. In: AQUINO, Julio Groppa (Org.). Autoridade e autonomia na escola: alternativas teóricas e práticas. São Paulo: Summus, 1999.

HIRSCHBERGER, Johannes. Historia de la filosofia II - Edad Moderna y Edad Contemporánea. Barcelona: Herder, 1997.

MATOS, Olgária Chain Féres. Teoria social no pensamento moderno Rousseau. In: Epistemologia das Ciencias Sociais [S.1: s.n.], 1985.

ROUSSEAU, Jean-Jacques. Discurso sobre as ciências e as artes e Discurso sobre a origem e os fundamentos da desigualdade entre os homens. São Paulo: Nova Cultural, 1999a. (Coleção Os Pensadores, v. 2).

ROUSSEAU, Jean-Jacques. O Emílio ou Da Educaşão. Trad. Roberto Leal Ferreira. 2. ed. São Paulo: Martins Fontes, 1999b.

ROUSSEAU, Jean-Jacques. Do Contrato Social. São Paulo: Nova Cultural, 1999c. (Coleção Os Pensadores, v. 1).

SALOMON-BAYET, Claire. Jean-Jacques Rousseau. In: CHÂTELET, François. História da Filosofia: a filosofia de Galileu a J.-J. Rousseau. Lisboa: Dom Quixote, 1981. 
SPAEMANN, Robert. Rousseau, cittadino senza patria - dalla "polis" alla natura. Milão: Ares, 2009.

STAROBINSKI, Jean. Jean-Jacques Rousseau: a transparência e o obstáculo. São Paulo: Companhia das Letras, 1991. 